\title{
Do forecasters inform or reassure? Evaluation of the German real-time $\operatorname{data}^{\S}$
}

\author{
Konstantin A. Kholodilin* Boriss Siliverstovs**
}

September 26, 2008

\begin{abstract}
The paper evaluates the quality of the German national accounting data (GDP and its components) as measured by the magnitude and dispersion of the forecast/revision errors. It is demonstrated that government consumption series are the least reliable, whereas nominal exports and imports and real GDP data are the most reliable. In addition, early forecasts of GDP, private consumption, and investment data are shown to be upward biased. Finally, early forecasts of all the variables seem to be no more accurate than naive guessing based on the unconditional distribution of the final data.
\end{abstract}

Keywords: Quality of statistical data; real-time data; signal-to-noise ratio; forecasts; revisions.

JEL classification: C53; C89

\footnotetext{
$\S$ We are grateful to Alexey Teterukovsky for his helpful comments.

*DIW Berlin, Mohrenstraße 58, 10117 Berlin, Germany, e-mail: kkholodilin@diw.de

**ETH Zurich, KOF Swiss Economic Institute, Weinbergstraße 35, 8092 Zurich, Switzerland, e-mail: boriss.siliverstovs@kof .ethz.ch
} 


\section{Contents}

1 Introduction 1

2 Data 2

3 Revision measures $\quad 3$

4 Results 5

4.1 Nominal variables . . . . . . . . . . . . . . . . 5

4.2 Real variables . . . . . . . . . . . . . . . 7

$\begin{array}{llr}5 & \text { Conclusions } & 8\end{array}$

$\begin{array}{lr}\text { References } & 9\end{array}$

$\begin{array}{lr}\text { Appendix } & 11\end{array}$ 


\section{List of Tables}

1 Descriptive statistics of the forecast/revision errors: nominal variables . . . . . . . . . . . . . . . . . . . . . 11

2 Descriptive statistics of the forecast/revision errors: real variables ....................... . . 13

3 Testing hypothesis of mean revision error equal zero (nominal variables): p-values of t-test . . . . . . . . . . . . . . 16

4 Testing hypothesis of revision-error variances greater than variance of last revision (nominal variables): p-values of F-test . . 17

5 Testing hypothesis of mean revision error equal zero (real variables): p-values of t-test . . . . . . . . . . . . . 17

6 Testing hypothesis of revision-error variances greater than variance of last revision (real variables): p-values of F-test . . . . 18

7 Integrated SNR measure . . . . . . . . . . . . . 19

\section{List of Figures}

1 Sequence of forecasts/revisions for the reporting period $t$. . . 20

2 First forecast $(t-3 / 2)$ vs. final nominal data $(t+1)$, 1996-2006 21

3 First forecast $(t-3 / 2)$ vs. final real data $(t+1), 1996-2006$. 22

4 First statistical publication $(t+1 / 4)$ vs. final nominal data $(t+1), 1996-2006 \ldots \ldots \ldots \ldots . \ldots \ldots$

$5 \quad$ First statistical publication $(t+1 / 4)$ vs. final real data $(t+1)$, 1996-2006 ..................... 24

6 Distribution of the revision errors of the nominal variables . . 25

7 Distribution of the revision errors of the real variables . . . . . 26

8 SNR of the nominal variables . . . . . . . . . . . . . 27

9 SNR of the real variables . . . . . . . . . . . . . 28 


\section{Introduction}

The significance of precise knowledge of the current state of the economy as well as of ability to accurately forecast macroeconomic variables in the future is difficult to overestimate. Clearly, no well-defined policy decision could be made without reliable information on the developments in the economy and its future prospects. Consequently, considerable literature has evolved dealing with assessment of macroeconomic forecast accuracy as well as investigating statistical properties of data revisions. In assessing of forecast accuracy, together with testing for forecast rationality and unbiasedness, a considerable attention has been paid to determining the information content of forecasts (e.g., see Parzen, 1982; Öller, 1985; de Gooijer and Klein, 1992; Diebold and Kilian, 2001; Oke and Öller, 1999; Galbraith, 2003; Isiklar and Lahiri, 2007; Öller and Teterukovsky, 2007). For example, Öller (1985), Oke and Öller (1999) and Galbraith (2003) by fitting the ARIMA-type processes attempt to determine the information content of optimal forecasts depending on the length of the forecast horizon. Diebold and Kilian (2001) propose a simple measure of relative predictability where they compare the expected loss of a short-run forecast to the expected loss of a long-run forecast. de Gooijer and Klein (1992) estimate the optimal forecast horizon for cumulated multi-step predictions. Isiklar and Lahiri (2007) evaluate the flow of new information contained in monthly GDP forecasts provided by Consensus Economics. They report that beyond the 14 months the forecasts have little if any value. Öller and Teterukovsky (2007) suggest a new measure that can be used to assess the information content of forecasts based on ratio of the variance of forecasts at a given horizon to the unconditional variance of the time series under investigation.

A related strand of research assesses the quality of the current data available in real-time by investigating statistical properties of data revisions, i.e., by comparing the first or preliminary data announcements usually made shortly after the end of the forecast period with the ultimate revision figures, often reported years after the initial estimate. If data revisions appear to be rather large and volatile then it is likely that the quality of the first-round estimates is poor (McNees, 1989; Mankiw and Shapiro, 1986; Faust et al., 2005; Swanson and van Dijk, 2006, among others).

In our paper, we evaluate the quality of both forecasts and statistical data revisions using the real time data set for Germany. To this end we employ

the novel technique suggested in Öller and Teterukovsky (2007) applied to 
the growth rates of the German GDP and its demand-side components. We use forecasts provided by the leading German economic institutes during the so-called Gemeinschaftsdiagnose (GD, or Joint Forecast). There are three reasons, why GD forecasts are used here. First, GD plays a very important role in providing informational support to the economic policy decisions made by the German government, on behalf (and money) of which these forecasts are made. Second, it represents not the opinion of a single forecasting institute but rather a consensus attained by several institutes. Third, it is the only institution that makes macroeconomic forecasts for Germany at such a level of decomposition.

To the best of our knowledge, such a detailed evaluation of the quality of forecasts and statistical data revisions of the GDP and its components for Germany using the real-time data has not been done so far. The previous literature either focuses on forecasts or revisions of the German GDP reported together with forecasts/revisions made for other countries like Faust et al. (2005) and Isiklar and Lahiri (2007), respectively, or it focuses exclusively on data revisions for industrial production like in Jacobs and Sturm (2004) and Knetsch and Reimers (2006).

Our main findings are as follows. Firstly, we found that both nominal and real government consumption data are the least reliable, while the nominal exports and nominal imports as well as of the real GDP data are the most reliable series. Here, the reliability is measured by the overall information content of the variables across all the vintages. Secondly, the first vintages (actually, forecasts) of GDP, private consumption, and investment data (up to vintage $t-1 / 2$ ) appear to be upward biased. Thirdly, the forecasts of all variables until the vintage $t-1 / 2$ seem to be no more accurate than naive guessing based on the unconditional distribution of the final data.

The remainder of the paper is structured as follows. Section 2 describes the data set used in the analysis. Section 3 introduces the measurement techniques used here to evaluate the quality of statistical data. Section 4 discusses the results of data quality evaluation. Finally, section 5 concludes.

\section{Data}

Two data sets are used in this study. The first data set contains the forecasts of the annual growth rates made twice a year (Spring, normally in April, and Fall, typically in October) by the leading German macroeconomic forecast 
institutes during the so-called Gemeinschaftsdiagnose ${ }^{1}$ ) and covers the period Spring 1995 — Spring 2008. During each GD meeting (except Spring 1995 and Spring 1996) the forecasts for the current and next year are made. The second data set is comprised of the quarterly publications of the quarterly SNA statistics by the Statistisches Bundesamt Deutschlands (StaBu, or German Federal Statistical Office ${ }^{2}$ ) starting in 1997Q1 and ending in 2008Q2 and covers the real-time data over the period 1995:Q2-2008:Q1. Unfortunately, earlier data are not available, because prior to $1995 \mathrm{StaBu}$ was only publishing West German SNA statistics.

Both data sets include the following 8 variables: GDP, private consumption, government consumption, total investment, investment in equipment, investment in construction, exports, and imports. Both nominal and real variables are considered. Based on these data sets a combined data set was constructed, which contains the quarterly vintages of the forecast and revised data on the annual growth rates of the German GDP and its components. The GD Spring and Fall data were assigned to the second and fourth quarters, respectively.

To the best of our knowledge, this is a unique database, which has never been used before to conduct any economic analysis.

\section{Revision measures}

The purpose of this study is to evaluate the quality of German statistical data. The quality here is measured by the size and dynamics of forecast/revision errors with respect to some "true" value of the variables in question. It is assumed that, although this true value is never observed, it is well approximated by the final revision value. Hence the revision error is defined as:

$$
e_{t}^{l}=y_{t}^{L}-y_{t}^{l}
$$

\footnotetext{
${ }^{1}$ The GD data are taken from its regular forecast publications, which are available for the period Spring 1995 — Spring 2007 on the webpage of the DIW Berlin http: //www.diw.de/deutsch/produkte/publikationen/wochenbericht/29864.html and for the period Fall 2007 - Spring 2008 on the webpage of the IWH http://www . iwh-halle. de/asp/publist . asp?Lang=d\&Reihe=1

${ }^{2}$ Statistisches Bundesamt, Fachserie 18 Reihe 1.2, Volkswirtschaftliche Gesamtrechnungen, Inlandsproduktsberechnung, Vierteljahresergebnisse.
} 
where $y_{t}^{l}$ is the $l$-th revision carried out in period $t ; L$ is the period, when final revision is made. The final revision is supposed to happen in the period $t+1$, that is, one year after the period, to which it refers. This contradicts the official definition of the final data, according to which the data become final in the period $t+4$ (see Statistisches Bundesamt (2007), p. 7). However, as our calculations have shown, after one year almost all the revision errors are equal to zero.

The sequence of GD forecasts and $\mathrm{StaBu}$ revisions is illustrated in Figure 1. The first four estimates of the variable of interest, starting from $t-3 / 2$ and ending in $t$, are the fore- or nowcasts made by the GD, whereas the last four estimates are the revisions produced by the StaBu.

The forecast/revision errors can be summarized using the measure of the mean squared error (MSE):

$$
M S E_{l}=\frac{1}{T} \sum_{t=1}^{T} e_{t}^{l}
$$

Thus, MSE measures the variance of the forecast/revision errors.

Based on the MSE, an information measure, also known as signal-to-noise ratio (SNR), can be computed:

$$
I_{l}=1-\frac{M S E_{l}}{\sigma_{L}^{2}}
$$

where $\sigma_{L}^{2}$ is the variance of the final revision, $y_{t}^{L}$. SNR measures the information content of each forecast/revision. It can be interpreted as a goodness of fit of each revision. It is expected that as more information comes in, the variance of forecast/revision errors goes to zero and the SNR approaches 1.

In order to evaluate the overall quality of data, Öller and Teterukovsky (2007) have introduced the integrated SNR measure, which is defined as:

$$
I=\frac{1}{2} \sum_{l=0}^{L-1}\left(I_{l}+I_{l+1}\right) \tau(l, l+1)
$$

where $\tau(l, l+1)$ is the interval between the vintages $l$ and $l+1$. Without loss of generality, the time interval between the first forecast and last revision can be re-scaled to the $[0,1]$ interval. In that case, the integrated SNR measure will vary between 0 (complete ignorance about the final value up to the last revision) and 1 (the very first forecast conveys all necessary information about the final value). 


\section{Results}

\subsection{Nominal variables}

First, let us compare the very first forecast made in period $t-3 / 2$ to the final values (StaBu publication in period $t+1)$. Figure 2 depicts the first forecast (dashed line), last official publication (bold continuous line) as well as forecast errors (grey bars). The forecasts for 1995 and 1996 are missing, since, as already mentioned, the Spring GD did not publish the next-year forecasts until 1997. As seen, the first forecast is quite different from the final data. Moreover, the forecasts of the overall GDP, private consumption, and both types of investment are upward biased over almost all the sample period. Figure 4 compares the data of the first official publication to the final data. In striking contrast to the first forecast, the first official publication produces much closer results to the last vintage. This is to be expected, given a larger amount of relevant information that is accumulated by the period $t$, albeit the forecast/revision error reduction happening between the first forecast and first official publication is huge. Higher revision errors, displayed by the grey bars, are observed in case of GDP and private consumption.

Next, consider the descriptive statistics of the forecast/revision errors $\left(e_{t}^{l}\right)$ computed for each vintage and each variable, see Table 1 and Figure 6. Firstly, note that in the vintage $t+3 / 4$, that is a quarter before the final data are published, the distribution of revision errors for all variables but imports is degenerated. It means that official data published in $t+3 / 4$ have already converged to the final data. This supports our choice of $t+1$ vintage as that corresponding to the final revision. Secondly, observe that the mean and median of GDP, private consumption, investment in equipment, and investment in construction is negative from the vintage $t-3 / 2$ till the vintage $t$. This confirms the upward biasedness of these forecasts noted already above. The interesting thing here is that the bias does not entirely disappear until the last forecast. In addition, one can see in Figure 6 that in the case of GDP the convergence of mean/median towards zero over vintages is far from being gradual: after vintage $t-1$ the mean error jumps up substantially. This may to do with the way the GD makes its forecasts for the next year. The bias is particularly severe in the case of GDP and private consumption, as the mean-to-range ratio is the highest for these variables. Thirdly, the decline in standard deviation of forecast/revision errors $\left(\sigma_{l}\right)$ over vintage horizon is noticeable. In fact, as Figure 6 shows, the dispersion of 
forecast/revision errors goes down steadily as the last revision approaches. It implies that for all variables the accuracy of published data continuously increases towards the last official publication. Fourthly, in case of GDP, private consumption, and investment in equipment $\sigma_{l} / \sigma_{L}$ exceeds 1 in the vintage $t-3 / 2$, whereas in case of other variables it is greater than one also in the vintage $t-1$. However, after the first two vintages this ratio is smaller than 1 and converging towards 0 . This means that the first two forecasts are probably less informative than a naive inference based on drawing random numbers from unconditional distribution of final values and using them as forecasts. This hypothesis will be tested more formally in what follows.

Given the fact that in some instances the forecast errors seem to differ substantially from zero, we test at different vintages the null hypothesis of the mean of forecast/revision errors being equal to one. The rejection of this hypothesis would suggest that the forecasts/revisions are biased. The results ( $p$-values) of the test are reported in Table 3. The null of zero mean is rejected at $5 \%$ level for the vintages $t-3 / 2$ and $t-1$ of GDP as well as for the vintages $t-3 / 2, t-1$, and $t-1 / 2$ of private consumption. Hence, one can suggest that the first GD forecasts of these two variables are overly optimistic. At $10 \%$ level the null can also be rejected in case of both investment variables also up to horizon $t-1 / 2$. However, one has to be cautious when interpreting these results, given a very short sample size. The same caveat applies to the null rejection for exports and imports in the vintages $t+1 / 4$ and $t+1 / 2$.

Further, we test whether the forecasts/revisions allow to improve significantly over the "full ignorance". The full ignorance here is represented by the unconditional distribution of the final values of variables. In this case, a completely ignorant forecaster picks up randomly a number from this distribution and uses it as a naive prediction. The test for full ignorance then boils down to comparing the variances of forecast/revision errors to that of the final data. The null hypothesis states that the variances are equal, while alternative hypothesis means that the former variance is lower than the latter. Table 4 reports the $p$-values of this test. One can see that until the vintage $t-1 / 2$ the null hypothesis cannot be rejected even at $10 \%$ level of significance. It means that first three forecasts are hardly more accurate than a naive forecast.

The integrated SNR measures for both nominal and real variables are reported in Table 4. Nominal government consumption has the lowest value of information measure $I$, followed by the nominal GDP and private consumption, which corroborates the results of our previous tests. By contrast, 
exports and imports have the largest integrated SNR. This is a reasonable result, given that information on foreign trade is easier to collect and is generally considered as more reliable. In addition, Table 4 reports the period, by which half of the information content is accumulated (the first $50 \%$ of the integrated SNR). The earlier this happens the timelier is the variable. According to this indicator, the most timely variable is nominal GDP, since half of information about its true value is available already 1-2 quarters before the reporting period. The least timely variable is nominal government consumption, for which $50 \%$ of information become available only after the reporting period.

The evolution of the information content of the German nominal SNA data over vintages is illustrated in Figure 8. The horizontal axis shows the vintages from $t-3 / 2$ till $t+1$, whereas the vertical axis displays the SNR at each vintage. Black area represents the lack of knowledge. In the case of perfect knowledge, the whole information about the true value of variable is known already in the very beginning and hence the area of the graph is completely white. In the opposite case, when until the very last revision no information is available, the area of the graph should be completely black. In fact, integrated SNR measures the white area of the graph. Firstly, the SNR of all variables, except for exports, is equal to 0 in the first two vintages. By construction it means that the variance of forecast errors is higher than or equal to the variance of "full ignorance" distribution. Thus, it confirms our above conclusion that the first forecasts are hardly of any practical use. From vintage $t-1 / 2$ on the accuracy steadily increases and exceeds 0.8 by the time of the last forecast, $t$. It implies that the last forecast, which is actually a nowcast, can be considered as a first reasonable approximation to the "true" value of the data. The first official publications represent first a certain deceleration and then after the vintage $t+1 / 2$ acceleration in the process of accumulating the relevant information, as illustrated by the slope of the SNR curve. This is especially true in the case of exports and imports, which are very close to the final values already in the vintage $t$.

\subsection{Real variables}

The inspection of boxplots (see Figure 7) and descriptive statistics (see Table 2) of the real variables shows that forecasts/revisions of the GDP, private consumption, total investment, and investment in equipment are overestimated, whereas those of imports and exports are underestimated. In the 
case of government consumption, there is no clear pattern. However, the null hypothesis of the mean of forecast/revision errors equal 0 is rejected at $5 \%$ level only for the private consumption for the first two vintages $(t-3 / 2$ and $t-1$ ) as Table 5 shows.

The results of testing the null of "total ignorance" are similar to those obtained for the nominal variables: compare Table 4 and Table 6 . The only notable exception is the government consumption. Whereas for the nominal government consumption the null hypothesis can be rejected already for the vintage $t+1 / 4$, for the real government consumption this hypothesis can be rejected only starting in period $t+1 / 2$. This implies that there is more uncertainty around real government consumption than around nominal one.

Compared to what we had in the case of nominal variables, the best real variable in terms of the integrated SNR measure is now GDP (SNR=0.589) and not exports and imports, see Table 7 . This reversal of roles can be explained by the varying quality of corresponding deflators. The worst variable is again government consumption having the lowest integrated SNR $(\mathrm{SNR}=0.336)$. Real GDP is also the best in terms of speed of accumulating half of the information about its final values - already 2 quarters before the reporting date integrated SNR attains 50\%. Government consumption once again is the worst variable, according to this indicator. Its integrated SNR measure becomes 0.5 only almost 2 quarters after the reporting period.

In addition, as Figure 9 shows, in the period $t-1$ the information content of real government consumption worsens, whereas for all other variables it steadily increases. This surprising finding can be related to a short length of our sample.

\section{Conclusions}

In this paper, the quality of German SNA data was evaluated. In particular, the forecast/revision errors of the GDP and its use components were investigated.

It appears that both nominal and real government consumption data have the poorest quality, while the quality of the nominal exports and nominal imports as well as of the real GDP data is the highest. Moreover, the first vintages (actually, forecasts) of GDP and private consumption appear to be upward biased. In addition, the forecasts of all variables until the vintage $t-$ $1 / 2$ seem to be not significantly better than the naive, or ignorant, guessing. 
All in all, the reasonable forecasts - unbiased and significantly better than total ignorance - cannot be obtained before the vintage $t$, that is, the last quarter of the year, for which the forecast is made. These conclusions draw serious doubts on the meaningfulness of the early forecasts. It appears that the forecasts made for the next year perform rather reassuring function inducing economic agents to look more optimistically in the nearest future. Unfortunately, these overly rosy forecasts are usually not self fulfilling.

\section{References}

de Gooijer, J. G. and A. Klein (1992). On the cumulated multi-step-ahead predictions of vector autoregressive moving average processes. International Journal of Forecasting 7(4), 501-513.

Diebold, F. X. and L. Kilian (2001). Measuring predictability: theory and macroeconomic applications. Journal of Applied Econometrics 16(6), 657669.

Faust, J., J. H. Rogers, and J. H. Wright (2005). News and noise in G-7 GDP announcements. Journal of Money, Credit and Banking 37(3), 403-419.

Galbraith, J. (2003). Content horizons for univariate time series forecasts. International Journal of Forecasting 19(1), 43-55.

Isiklar, G. and K. Lahiri (2007). How far ahead can we forecast? Evidence from cross-country surveys. International Journal of Forecasting 23(2), $167-187$.

Jacobs, J. and J.-E. Sturm (2004). Do ifo indicators help explain revisions in german industrial production? Technical Report CESifo Working Paper No. 1205, CESifo GmbH.

Knetsch, T. A. and H.-E. Reimers (2006). How to treat benchmark revisions?: The case of German production and orders statistics. Discussion Paper Series 1: Economic Studies 2006, 38, Deutsche Bundesbank, Research Centre.

Mankiw, N. G. and M. D. Shapiro (1986). News or noise? analysis of gnp revisions. Survey of Current Business 66, 20-25. 
McNees, S. K. (1989). Forecasts and actuals: The trade-off between timeliness and accuracy. International Journal of Forecasting 5(3), 409-416.

Oke, T. and L.-E. Öller (1999). Testing for short memory in a VARMA process. International Journal of Forecasting 18, 477-487.

Öller, L.-E. (1985). How far can changes in business activity be forecast? International Journal of Forecasting 1, 135-141.

Öller, L.-E. and A. Teterukovsky (2007). Quantifying the quality of macroeconomic variables. International Journal of Forecasting 23(2), 205-217.

Parzen, E. (1982). ARARMA models for time series analysis and forecasting. Journal of Forecasting 1(1), 67-82.

Statistisches Bundesamt (2007). Volkswirtschaftliche Gesamtrechnungen: Qualitätsbericht.

Swanson, N. R. and D. van Dijk (2006). Are statistical reporting agencies getting it right? Data rationality and business cycle asymmetry. Journal of Business 83 Economic Statistics 24, 24-42. 


\section{Appendix}

Table 1: Descriptive statistics of the forecast/revision errors: nominal variables

\begin{tabular}{|c|c|c|c|c|c|c|c|}
\hline Statistic & $\mathrm{t}-3 / 2$ & $\mathrm{t}-1$ & $\mathrm{t}-1 / 2$ & $\mathrm{t}$ & $\mathrm{t}+1 / 4$ & $t+1 / 2$ & $t+3 / 4$ \\
\hline & \multicolumn{6}{|c|}{ GDP } & \\
\hline Minimum & -2.71 & -2.13 & -1.17 & -0.63 & -0.49 & -0.16 & 0.00 \\
\hline Maximum & 0.76 & 1.46 & 0.96 & 0.46 & 0.50 & 0.46 & 0.00 \\
\hline Range & 3.47 & 3.59 & 2.13 & 1.09 & 1.00 & 0.61 & 0.00 \\
\hline Median & -1.40 & -0.95 & -0.15 & -0.17 & 0.05 & 0.05 & 0.00 \\
\hline Mean & -1.14 & -0.84 & -0.18 & -0.15 & 0.05 & 0.10 & 0.00 \\
\hline$\sigma_{l}$ & 0.98 & 0.96 & 0.51 & 0.34 & 0.24 & 0.19 & 0.00 \\
\hline \multirow[t]{2}{*}{$\sigma_{l} / \sigma_{L}$} & 1.43 & 1.38 & 0.74 & 0.49 & 0.34 & 0.27 & 0.00 \\
\hline & \multicolumn{6}{|c|}{ Private consumption } & \\
\hline Minimum & -3.19 & -2.49 & -1.79 & -0.65 & -0.48 & -0.48 & 0.00 \\
\hline Maximum & 0.14 & 0.84 & 0.54 & 0.93 & 0.70 & 0.54 & 0.01 \\
\hline Range & 3.33 & 3.33 & 2.33 & 1.57 & 1.18 & 1.02 & 0.01 \\
\hline Median & -0.80 & -0.77 & -0.61 & -0.15 & 0.19 & 0.15 & 0.00 \\
\hline Mean & -1.20 & -0.88 & -0.45 & -0.07 & 0.15 & 0.13 & 0.00 \\
\hline$\sigma_{l}$ & 1.00 & 0.86 & 0.68 & 0.51 & 0.31 & 0.31 & 0.00 \\
\hline \multirow[t]{2}{*}{$\sigma_{l} / \sigma_{L}$} & 1.02 & 0.88 & 0.70 & 0.53 & 0.32 & 0.31 & 0.00 \\
\hline & \multicolumn{6}{|c|}{ Government consumption } & \\
\hline Minimum & -1.77 & -1.74 & -1.74 & -1.15 & -0.84 & -0.84 & 0.00 \\
\hline Maximum & 0.52 & 0.60 & 0.90 & 0.90 & 0.27 & 0.32 & 0.00 \\
\hline Range & 2.29 & 2.35 & 2.65 & 2.06 & 1.10 & 1.16 & 0.00 \\
\hline Median & -0.29 & -0.28 & -0.45 & -0.37 & -0.22 & -0.20 & 0.00 \\
\hline Mean & -0.47 & -0.40 & -0.38 & -0.32 & -0.31 & -0.22 & 0.00 \\
\hline$\sigma_{l}$ & 0.77 & 0.79 & 0.82 & 0.66 & 0.34 & 0.37 & 0.00 \\
\hline \multirow[t]{2}{*}{$\sigma_{l} / \sigma_{L}$} & 0.79 & 0.81 & 0.83 & 0.67 & 0.34 & 0.37 & 0.00 \\
\hline & \multicolumn{7}{|c|}{ Total investment } \\
\hline
\end{tabular}


Table 1: Descriptive statistics of the forecast/revision errors: nominal variables (continued)

\begin{tabular}{|c|c|c|c|c|c|c|c|}
\hline Statistic & $\mathrm{t}-3 / 2$ & $\mathrm{t}-1$ & $\mathrm{t}-1 / 2$ & $\mathrm{t}$ & $\mathrm{t}+1 / 4$ & $\mathrm{t}+1 / 2$ & $t+3 / 4$ \\
\hline Minimum & -10.02 & -8.82 & -6.62 & -2.92 & -0.63 & -0.63 & 0.00 \\
\hline Maximum & 4.63 & 5.43 & 3.33 & 2.53 & 0.76 & 0.73 & 0.00 \\
\hline Range & 14.65 & 14.25 & 9.95 & 5.45 & 1.39 & 1.35 & 0.00 \\
\hline Median & -2.04 & -1.85 & -1.07 & -0.17 & 0.38 & 0.12 & 0.00 \\
\hline Mean & -3.18 & -2.78 & -1.50 & -0.18 & 0.21 & 0.12 & 0.00 \\
\hline$\sigma_{l}$ & 4.64 & 3.82 & 2.61 & 1.64 & 0.50 & 0.44 & 0.00 \\
\hline \multirow[t]{2}{*}{$\sigma_{l} / \sigma_{L}$} & 1.27 & 1.05 & 0.72 & 0.45 & 0.14 & 0.12 & 0.00 \\
\hline & \multicolumn{7}{|c|}{ Investment in equipment } \\
\hline Minimum & -16.17 & -12.90 & -11.40 & -6.10 & -1.06 & -1.06 & 0.00 \\
\hline Maximum & 4.00 & 2.84 & 3.00 & 2.65 & 1.93 & 1.93 & 0.00 \\
\hline Range & 20.16 & 15.73 & 14.39 & 8.75 & 2.99 & 2.99 & 0.00 \\
\hline Median & -2.83 & -1.53 & 0.47 & 0.20 & 0.16 & 0.01 & 0.00 \\
\hline Mean & -4.31 & -3.11 & -1.44 & -0.66 & 0.39 & 0.27 & 0.00 \\
\hline$\sigma_{l}$ & 7.27 & 5.52 & 4.63 & 2.87 & 0.86 & 0.82 & 0.00 \\
\hline \multirow[t]{2}{*}{$\sigma_{l} / \sigma_{L}$} & 1.23 & 0.93 & 0.78 & 0.49 & 0.14 & 0.14 & 0.00 \\
\hline & \multicolumn{7}{|c|}{ Investment in construction } \\
\hline Minimum & -7.19 & -6.39 & -3.59 & -2.66 & -0.69 & -0.69 & 0.00 \\
\hline Maximum & 7.47 & 7.97 & 4.87 & 3.57 & 0.96 & 0.50 & 0.00 \\
\hline Range & 14.67 & 14.37 & 8.47 & 6.24 & 1.65 & 1.19 & 0.00 \\
\hline Median & -3.40 & -3.34 & -2.17 & -0.10 & 0.05 & -0.06 & 0.00 \\
\hline Mean & -2.27 & -2.45 & -1.62 & 0.03 & 0.07 & -0.01 & 0.00 \\
\hline$\sigma_{l}$ & 4.19 & 4.06 & 2.34 & 1.61 & 0.44 & 0.34 & 0.00 \\
\hline \multirow[t]{2}{*}{$\sigma_{l} / \sigma_{L}$} & 1.27 & 1.23 & 0.71 & 0.49 & 0.13 & 0.10 & 0.00 \\
\hline & \multicolumn{7}{|c|}{ Exports } \\
\hline Minimum & -9.19 & -5.84 & -6.64 & -1.32 & -0.42 & -0.42 & 0.00 \\
\hline Maximum & 9.98 & 7.68 & 4.50 & 1.71 & 1.18 & 1.09 & 0.00 \\
\hline Range & 19.17 & 13.53 & 11.14 & 3.02 & 1.60 & 1.51 & 0.00 \\
\hline
\end{tabular}


Table 1: Descriptive statistics of the forecast/revision errors: nominal variables (continued)

\begin{tabular}{|c|c|c|c|c|c|c|c|}
\hline Statistic & $\mathrm{t}-3 / 2$ & $\mathrm{t}-1$ & $\mathrm{t}-1 / 2$ & $\mathrm{t}$ & $t+1 / 4$ & $t+1 / 2$ & $t+3 / 4$ \\
\hline Median & -1.52 & 0.37 & 2.38 & 0.58 & 0.56 & 0.41 & 0.00 \\
\hline Mean & -0.33 & 0.42 & 0.88 & 0.45 & 0.56 & 0.35 & 0.00 \\
\hline$\sigma_{l}$ & 5.83 & 4.65 & 3.80 & 1.03 & 0.43 & 0.44 & 0.00 \\
\hline$\sigma_{l} / \sigma_{L}$ & 1.30 & 1.03 & 0.85 & 0.23 & 0.09 & 0.10 & 0.00 \\
\hline & \multicolumn{7}{|c|}{ Imports } \\
\hline Minimum & -11.17 & -9.47 & -10.47 & -0.47 & -0.32 & -0.59 & 0.00 \\
\hline Maximum & 11.83 & 10.93 & 5.58 & 2.68 & 1.42 & 1.29 & 0.74 \\
\hline Range & 23.00 & 20.40 & 16.05 & 3.15 & 1.74 & 1.88 & 0.74 \\
\hline Median & -0.64 & 1.09 & 1.85 & 0.53 & 0.85 & 0.15 & 0.00 \\
\hline Mean & -0.60 & 0.09 & 0.51 & 0.77 & 0.58 & 0.36 & 0.11 \\
\hline$\sigma_{l}$ & 7.21 & 6.21 & 5.15 & 1.08 & 0.67 & 0.64 & 0.25 \\
\hline$\sigma_{l} / \sigma_{L}$ & 1.22 & 1.05 & 0.87 & 0.18 & 0.11 & 0.11 & 0.04 \\
\hline
\end{tabular}

Table 2: Descriptive statistics of the forecast/revision errors: real variables

\begin{tabular}{l|lllllll}
\hline Statistic & $\mathrm{t}-3 / 2$ & $\mathrm{t}-1$ & $\mathrm{t}-1 / 2$ & $\mathrm{t}$ & $\mathrm{t}+1 / 4$ & $\mathrm{t}+1 / 2$ & $\mathrm{t}+3 / 4$ \\
\hline & \multicolumn{7}{c}{ GDP } \\
\hline Minimum & -2.52 & -2.13 & -1.53 & -0.55 & -0.60 & -0.10 & 0.00 \\
Maximum & 1.36 & 1.66 & 1.06 & 0.56 & 0.18 & 0.10 & 0.00 \\
Range & 3.89 & 3.79 & 2.59 & 1.11 & 0.78 & 0.20 & 0.00 \\
Median & -0.60 & -0.65 & -0.05 & -0.14 & 0.02 & 0.01 & 0.00 \\
Mean & -0.83 & -0.57 & -0.12 & -0.06 & -0.02 & 0.01 & 0.00 \\
$\sigma_{l}$ & 1.29 & 1.00 & 0.70 & 0.29 & 0.20 & 0.06 & 0.00 \\
$\sigma_{l} / \sigma_{L}$ & 1.30 & 1.02 & 0.71 & 0.30 & 0.20 & 0.06 & 0.00 \\
& 170 & & & \\
\hline
\end{tabular}


Table 2: Descriptive statistics of the forecast/revision errors: real variables (continued)

\begin{tabular}{|c|c|c|c|c|c|c|c|}
\hline Statistic & $\mathrm{t}-3 / 2$ & $\mathrm{t}-1$ & $\mathrm{t}-1 / 2$ & $\mathrm{t}$ & $\mathrm{t}+1 / 4$ & $\mathrm{t}+1 / 2$ & $t+3 / 4$ \\
\hline Minimum & -3.12 & -2.52 & -1.62 & -0.70 & -0.38 & -0.38 & 0.00 \\
\hline Maximum & 0.48 & 1.16 & 0.59 & 0.89 & 0.95 & 0.65 & 0.00 \\
\hline Range & 3.60 & 3.68 & 2.21 & 1.59 & 1.33 & 1.02 & 0.00 \\
\hline Median & -1.12 & -0.95 & -0.54 & -0.15 & 0.20 & 0.20 & 0.00 \\
\hline Mean & -0.93 & -0.70 & -0.36 & 0.01 & 0.21 & 0.17 & 0.00 \\
\hline$\sigma_{l}$ & 1.15 & 1.03 & 0.66 & 0.58 & 0.34 & 0.30 & 0.00 \\
\hline \multirow[t]{2}{*}{$\sigma_{l} / \sigma_{L}$} & 1.15 & 1.03 & 0.66 & 0.58 & 0.34 & 0.30 & 0.00 \\
\hline & \multicolumn{7}{|c|}{ Government consumption } \\
\hline Minimum & -1.78 & -1.68 & -1.68 & -1.48 & -1.97 & -0.90 & -0.90 \\
\hline Maximum & 0.78 & 0.93 & 1.03 & 1.42 & 0.60 & 0.53 & 0.16 \\
\hline Range & 2.55 & 2.61 & 2.71 & 2.90 & 2.57 & 1.43 & 1.06 \\
\hline Median & 0.20 & -0.17 & 0.00 & -0.43 & -0.34 & -0.34 & 0.00 \\
\hline Mean & -0.30 & -0.33 & -0.19 & -0.28 & -0.48 & -0.30 & -0.10 \\
\hline$\sigma_{l}$ & 0.90 & 0.91 & 0.89 & 0.80 & 0.67 & 0.51 & 0.29 \\
\hline \multirow[t]{2}{*}{$\sigma_{l} / \sigma_{L}$} & 0.94 & 0.95 & 0.93 & 0.84 & 0.70 & 0.54 & 0.30 \\
\hline & \multicolumn{7}{|c|}{ Total investment } \\
\hline Minimum & -9.57 & -8.46 & -6.66 & -2.56 & -0.42 & -0.62 & 0.00 \\
\hline Maximum & 4.60 & 4.70 & 3.00 & 2.20 & 0.97 & 0.98 & 0.86 \\
\hline Range & 14.16 & 13.16 & 9.66 & 4.76 & 1.40 & 1.60 & 0.86 \\
\hline Median & -1.52 & -1.87 & -0.87 & -0.45 & 0.07 & 0.07 & 0.00 \\
\hline Mean & -2.71 & -2.28 & -1.22 & -0.19 & 0.27 & 0.22 & 0.08 \\
\hline$\sigma_{l}$ & 4.52 & 3.56 & 2.83 & 1.48 & 0.51 & 0.57 & 0.26 \\
\hline \multirow[t]{2}{*}{$\sigma_{l} / \sigma_{L}$} & 1.30 & 1.02 & 0.81 & 0.42 & 0.15 & 0.16 & 0.07 \\
\hline & \multicolumn{7}{|c|}{ Investment in equipment } \\
\hline Minimum & -15.64 & -12.97 & -11.67 & -6.07 & -0.88 & -0.93 & 0.00 \\
\hline Maximum & 4.60 & 3.82 & 2.82 & 2.83 & 2.11 & 2.11 & 0.00 \\
\hline Range & 20.23 & 16.79 & 14.49 & 8.91 & 2.99 & 3.04 & 0.00 \\
\hline
\end{tabular}


Table 2: Descriptive statistics of the forecast/revision errors: real variables (continued)

\begin{tabular}{|c|c|c|c|c|c|c|c|}
\hline Statistic & $\mathrm{t}-3 / 2$ & $\mathrm{t}-1$ & $\mathrm{t}-1 / 2$ & $\mathrm{t}$ & $t+1 / 4$ & $t+1 / 2$ & $t+3 / 4$ \\
\hline Median & -0.82 & -0.10 & 1.45 & -0.60 & 0.24 & 0.00 & 0.00 \\
\hline Mean & -3.08 & -2.24 & -0.98 & -0.64 & 0.52 & 0.22 & 0.00 \\
\hline$\sigma_{l}$ & 7.42 & 5.64 & 4.74 & 2.78 & 1.07 & 0.99 & 0.00 \\
\hline \multirow[t]{2}{*}{$\sigma_{l} / \sigma_{L}$} & 1.28 & 0.98 & 0.82 & 0.48 & 0.18 & 0.17 & 0.00 \\
\hline & \multicolumn{7}{|c|}{ Investment in construction } \\
\hline Minimum & -6.96 & -5.86 & -3.74 & -2.44 & -0.49 & -0.49 & 0.00 \\
\hline Maximum & 5.66 & 5.46 & 3.06 & 2.66 & 0.45 & 0.45 & 0.00 \\
\hline Range & 12.62 & 11.32 & 6.80 & 5.10 & 0.95 & 0.95 & 0.00 \\
\hline Median & -3.36 & -2.77 & -1.65 & -0.03 & 0.05 & -0.06 & 0.00 \\
\hline Mean & -2.37 & -2.16 & -1.66 & -0.07 & 0.03 & -0.03 & 0.00 \\
\hline$\sigma_{l}$ & 3.85 & 3.25 & 2.08 & 1.42 & 0.30 & 0.26 & 0.00 \\
\hline \multirow[t]{2}{*}{$\sigma_{l} / \sigma_{L}$} & 1.41 & 1.19 & 0.76 & 0.52 & 0.11 & 0.09 & 0.00 \\
\hline & \multicolumn{7}{|c|}{ Exports } \\
\hline Minimum & -6.55 & -4.28 & -5.08 & -0.89 & -0.41 & -0.51 & 0.00 \\
\hline Maximum & 8.53 & 6.33 & 4.30 & 2.50 & 2.71 & 0.82 & 0.00 \\
\hline Range & 15.08 & 10.61 & 9.37 & 3.39 & 3.11 & 1.33 & 0.00 \\
\hline Median & 0.49 & 0.97 & 2.71 & 0.73 & 0.60 & 0.34 & 0.00 \\
\hline Mean & 0.75 & 1.32 & 1.35 & 0.87 & 0.59 & 0.26 & 0.00 \\
\hline$\sigma_{l}$ & 4.71 & 3.64 & 3.16 & 1.07 & 0.80 & 0.43 & 0.00 \\
\hline \multirow[t]{2}{*}{$\sigma_{l} / \sigma_{L}$} & 1.30 & 1.01 & 0.87 & 0.29 & 0.22 & 0.12 & 0.00 \\
\hline & \multicolumn{7}{|c|}{ Imports } \\
\hline Minimum & -7.96 & -7.54 & -9.04 & -1.34 & -1.70 & -1.70 & 0.00 \\
\hline Maximum & 5.50 & 6.10 & 6.41 & 3.51 & 1.91 & 1.21 & 0.00 \\
\hline Range & 13.46 & 13.64 & 15.46 & 4.86 & 3.61 & 2.91 & 0.00 \\
\hline Median & 1.64 & 1.90 & 1.30 & 1.01 & 0.88 & 0.48 & 0.00 \\
\hline Mean & 0.17 & 0.60 & 0.84 & 1.15 & 0.62 & 0.34 & 0.00 \\
\hline$\sigma_{l}$ & 4.83 & 4.36 & 4.15 & 1.39 & 0.98 & 0.85 & 0.00 \\
\hline$\sigma_{l} / \sigma_{L}$ & 1.26 & 1.14 & 1.08 & 0.36 & 0.25 & 0.22 & 0.00 \\
\hline
\end{tabular}


Table 2: Descriptive statistics of the forecast/revision errors: real variables (continued)

\begin{tabular}{l|lllllll}
\hline Statistic & $\mathrm{t}-3 / 2$ & $\mathrm{t}-1$ & $\mathrm{t}-1 / 2$ & $\mathrm{t}$ & $\mathrm{t}+1 / 4$ & $\mathrm{t}+1 / 2$ & $\mathrm{t}+3 / 4$ \\
\hline & & & & & & & \\
\hline
\end{tabular}

Table 3: Testing hypothesis of mean revision error equal zero (nominal variables): $p$-values of t-test

\begin{tabular}{l|rrrrrrrr}
\hline & GDP & PCons & GCons & Inv & InvEqp & InvConstr & Exports & Imports \\
\hline $\mathrm{t}-3 / 2$ & 0.008 & 0.007 & 0.106 & 0.074 & 0.113 & 0.142 & 0.871 & 0.808 \\
$\mathrm{t}-1$ & 0.016 & 0.007 & 0.125 & 0.036 & 0.091 & 0.089 & 0.770 & 0.964 \\
$\mathrm{t}-1 / 2$ & 0.261 & 0.054 & 0.152 & 0.085 & 0.327 & 0.045 & 0.462 & 0.748 \\
$\mathrm{t}$ & 0.175 & 0.673 & 0.140 & 0.730 & 0.465 & 0.954 & 0.180 & 0.040 \\
$\mathrm{t}+1 / 4$ & 0.466 & 0.134 & 0.013 & 0.190 & 0.159 & 0.626 & 0.001 & 0.017 \\
$\mathrm{t}+1 / 2$ & 0.110 & 0.192 & 0.072 & 0.378 & 0.295 & 0.944 & 0.026 & 0.092 \\
$\mathrm{t}+3 / 4$ & NaN & 0.341 & NaN & NaN & NaN & NaN & 0.341 & 0.180 \\
\hline
\end{tabular}


Table 4: Testing hypothesis of revision-error variances greater than variance of last revision (nominal variables): p-values of F-test

\begin{tabular}{l|rrrrrrrr}
\hline & GDP & PCons & GCons & Inv & InvEqp & InvConstr & Exports & Imports \\
\hline $\mathrm{t}-3 / 2$ & 0.957 & 0.598 & 0.247 & 0.883 & 0.862 & 0.889 & 0.909 & 0.851 \\
$\mathrm{t}-1$ & 0.962 & 0.348 & 0.224 & 0.640 & 0.456 & 0.872 & 0.619 & 0.648 \\
$\mathrm{t}-1 / 2$ & 0.144 & 0.106 & 0.270 & 0.109 & 0.190 & 0.115 & 0.295 & 0.330 \\
$\mathrm{t}$ & 0.008 & 0.014 & 0.085 & 0.003 & 0.007 & 0.007 & 0.000 & 0.000 \\
$\mathrm{t}+1 / 4$ & 0.000 & 0.000 & 0.000 & 0.000 & 0.000 & 0.000 & 0.000 & 0.000 \\
$\mathrm{t}+1 / 2$ & 0.000 & 0.000 & 0.001 & 0.000 & 0.000 & 0.000 & 0.000 & 0.000 \\
$\mathrm{t}+3 / 4$ & 0.000 & 0.000 & 0.000 & 0.000 & 0.000 & 0.000 & 0.000 & 0.000 \\
\hline
\end{tabular}

Table 5: Testing hypothesis of mean revision error equal zero (real variables): $p$-values of t-test

\begin{tabular}{l|rrrrrrrr}
\hline & GDP & PCons & GCons & Inv & InvEqp & InvConstr & Exports & Imports \\
\hline $\mathrm{t}-3 / 2$ & 0.087 & 0.042 & 0.352 & 0.110 & 0.249 & 0.125 & 0.646 & 0.920 \\
$\mathrm{t}-1$ & 0.088 & 0.047 & 0.283 & 0.059 & 0.217 & 0.081 & 0.258 & 0.660 \\
$\mathrm{t}-1 / 2$ & 0.586 & 0.102 & 0.505 & 0.205 & 0.506 & 0.024 & 0.186 & 0.517 \\
$\mathrm{t}$ & 0.544 & 0.950 & 0.279 & 0.677 & 0.463 & 0.879 & 0.022 & 0.020 \\
$\mathrm{t}+1 / 4$ & 0.790 & 0.073 & 0.039 & 0.112 & 0.136 & 0.756 & 0.034 & 0.060 \\
$\mathrm{t}+1 / 2$ & 0.516 & 0.097 & 0.078 & 0.236 & 0.471 & 0.685 & 0.078 & 0.219 \\
$\mathrm{t}+3 / 4$ & NaN & 0.223 & 0.294 & 0.341 & NaN & NaN & NaN & NaN \\
\hline
\end{tabular}


Table 6: Testing hypothesis of revision-error variances greater than variance of last revision (real variables): p-values of F-test

\begin{tabular}{l|rrrrrrrr}
\hline & GDP & PCons & GCons & Inv & InvEqp & InvConstr & Exports & Imports \\
\hline $\mathrm{t}-3 / 2$ & 0.905 & 0.773 & 0.472 & 0.905 & 0.891 & 0.949 & 0.907 & 0.874 \\
$\mathrm{t}-1$ & 0.586 & 0.615 & 0.490 & 0.604 & 0.492 & 0.820 & 0.575 & 0.776 \\
$\mathrm{t}-1 / 2$ & 0.109 & 0.075 & 0.449 & 0.252 & 0.244 & 0.176 & 0.338 & 0.688 \\
$\mathrm{t}$ & 0.000 & 0.037 & 0.265 & 0.002 & 0.007 & 0.013 & 0.000 & 0.001 \\
$\mathrm{t}+1 / 4$ & 0.000 & 0.000 & 0.099 & 0.000 & 0.000 & 0.000 & 0.000 & 0.000 \\
$\mathrm{t}+1 / 2$ & 0.000 & 0.000 & 0.018 & 0.000 & 0.000 & 0.000 & 0.000 & 0.000 \\
$\mathrm{t}+3 / 4$ & 0.000 & 0.000 & 0.000 & 0.000 & 0.000 & 0.000 & 0.000 & 0.000 \\
\hline
\end{tabular}


Table 7: Integrated SNR measure

\begin{tabular}{l|ll|ll}
\hline & \multicolumn{2}{|c|}{ Nominal } & \multicolumn{2}{c}{ Real } \\
\cline { 2 - 5 } & SNR & $\begin{array}{l}\text { Half info, } \\
\text { quarter }\end{array}$ & SNR & $\begin{array}{l}\text { Half info, } \\
\text { quarter }\end{array}$ \\
\hline GDP & 0.526 & -1.5 & 0.589 & -2.1 \\
Private consumption & 0.508 & -1.2 & 0.524 & -1.8 \\
Government consumption & 0.498 & 0.1 & 0.336 & 1.6 \\
Total investment & 0.542 & -1.4 & 0.526 & -1.2 \\
Investment in equipment & 0.538 & -1.4 & 0.532 & -1.3 \\
Investment in construction & 0.525 & -1.2 & 0.481 & -0.8 \\
Exports & 0.553 & -1.4 & 0.504 & -1.0 \\
Imports & 0.549 & -1.4 & 0.455 & -0.7 \\
\hline
\end{tabular}

Note: Half info, quarter $=$ quarter, by which half of the information about the true value of variable is accumulated. 
Figure 1: Sequence of forecasts/revisions for the reporting period $t$

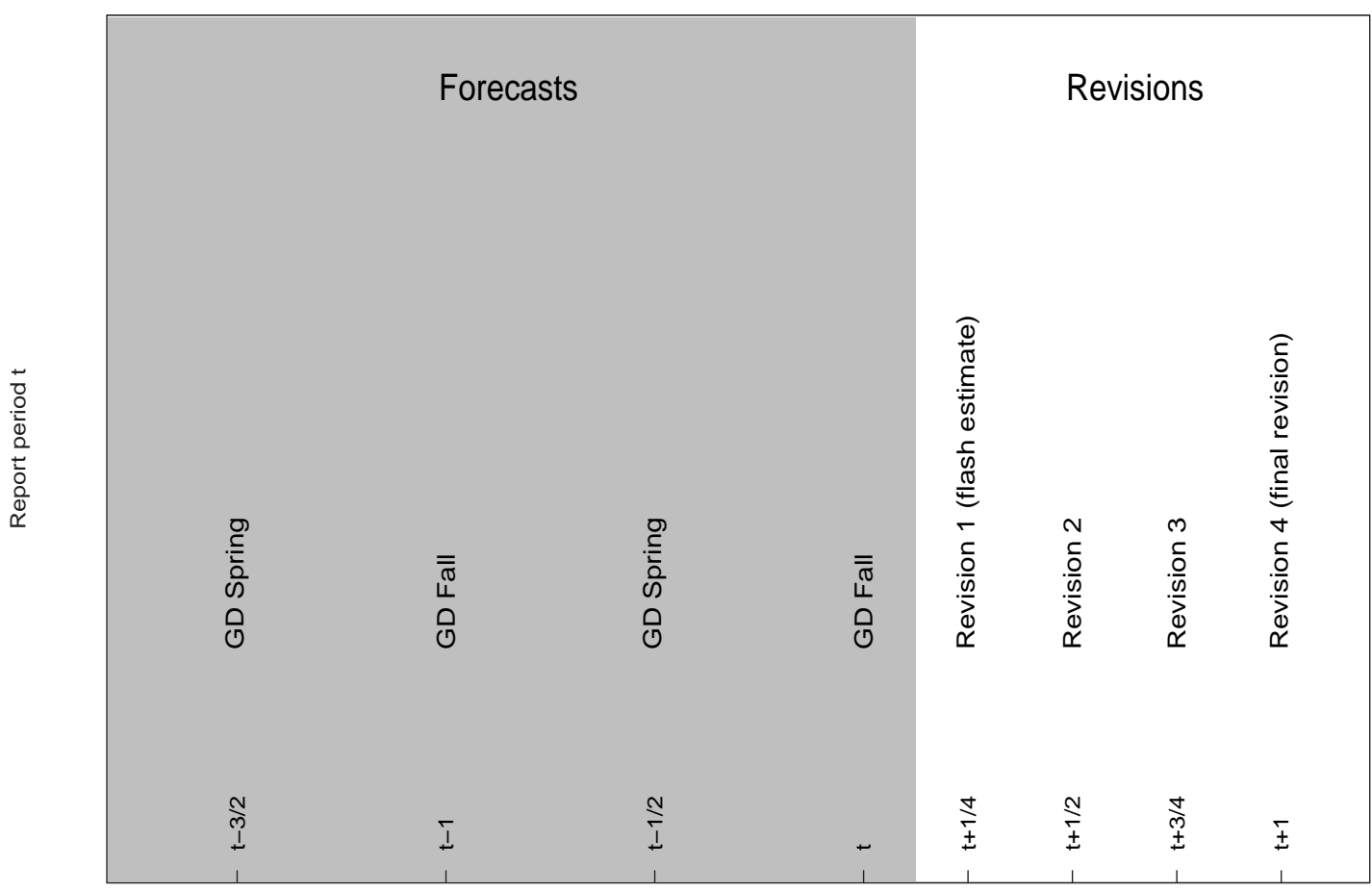

Vintage periods 
Figure 2: First forecast $(t-3 / 2)$ vs. final nominal data $(t+1)$, 1996-2006
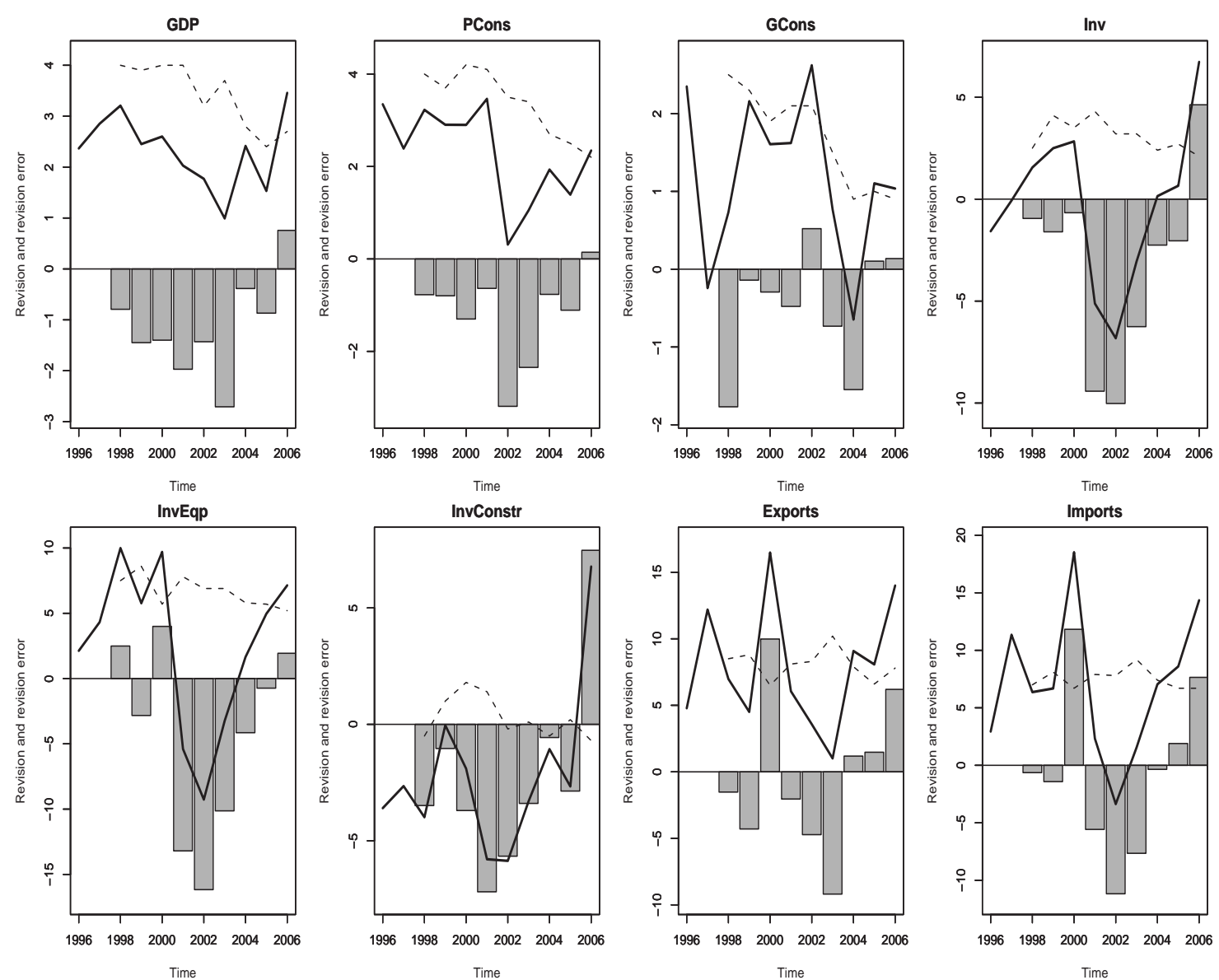
Figure 3: First forecast $(t-3 / 2)$ vs. final real data $(t+1)$, 1996-2006
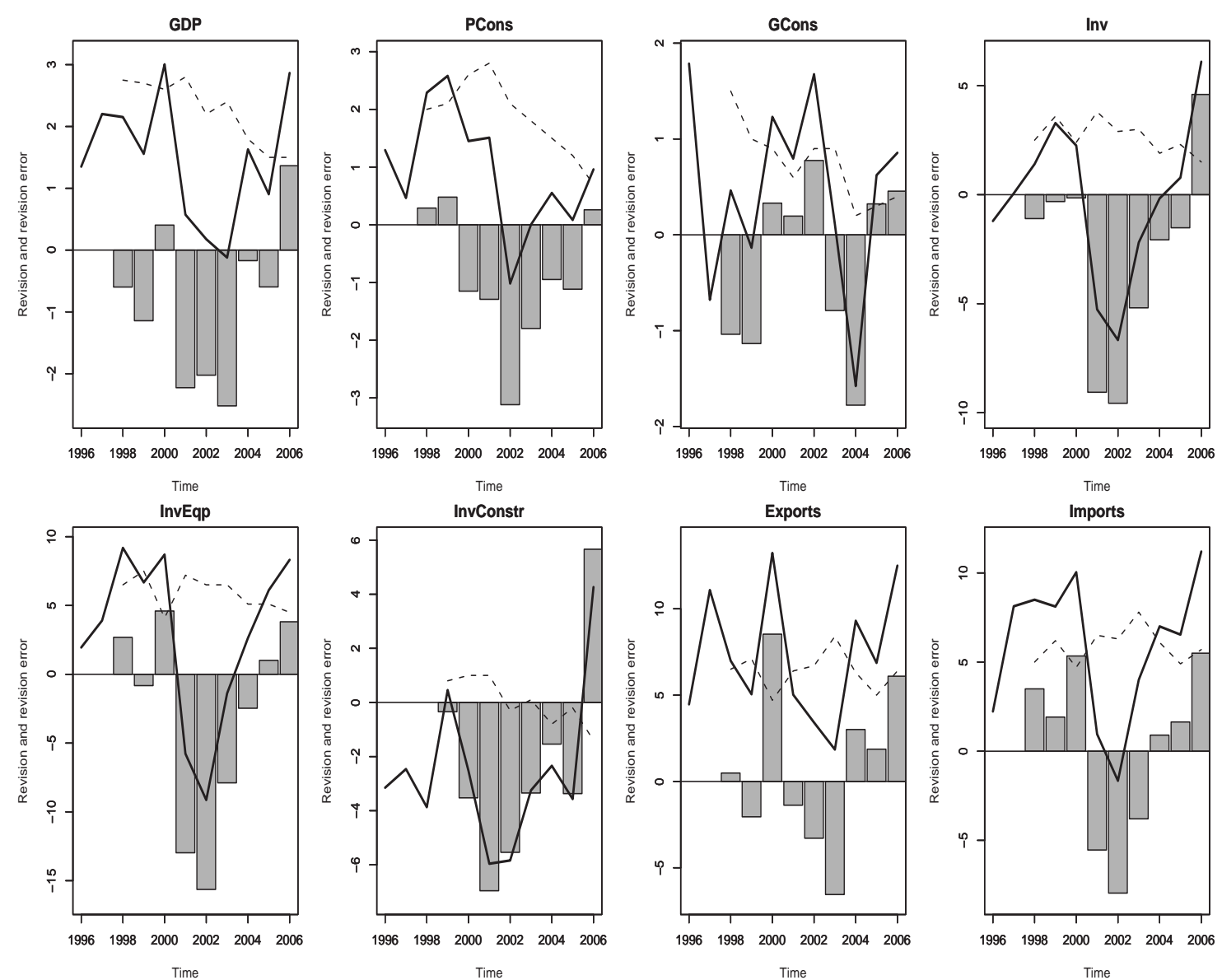
Figure 4: First statistical publication $(t+1 / 4)$ vs. final nominal data $(t+1)$, 1996-2006
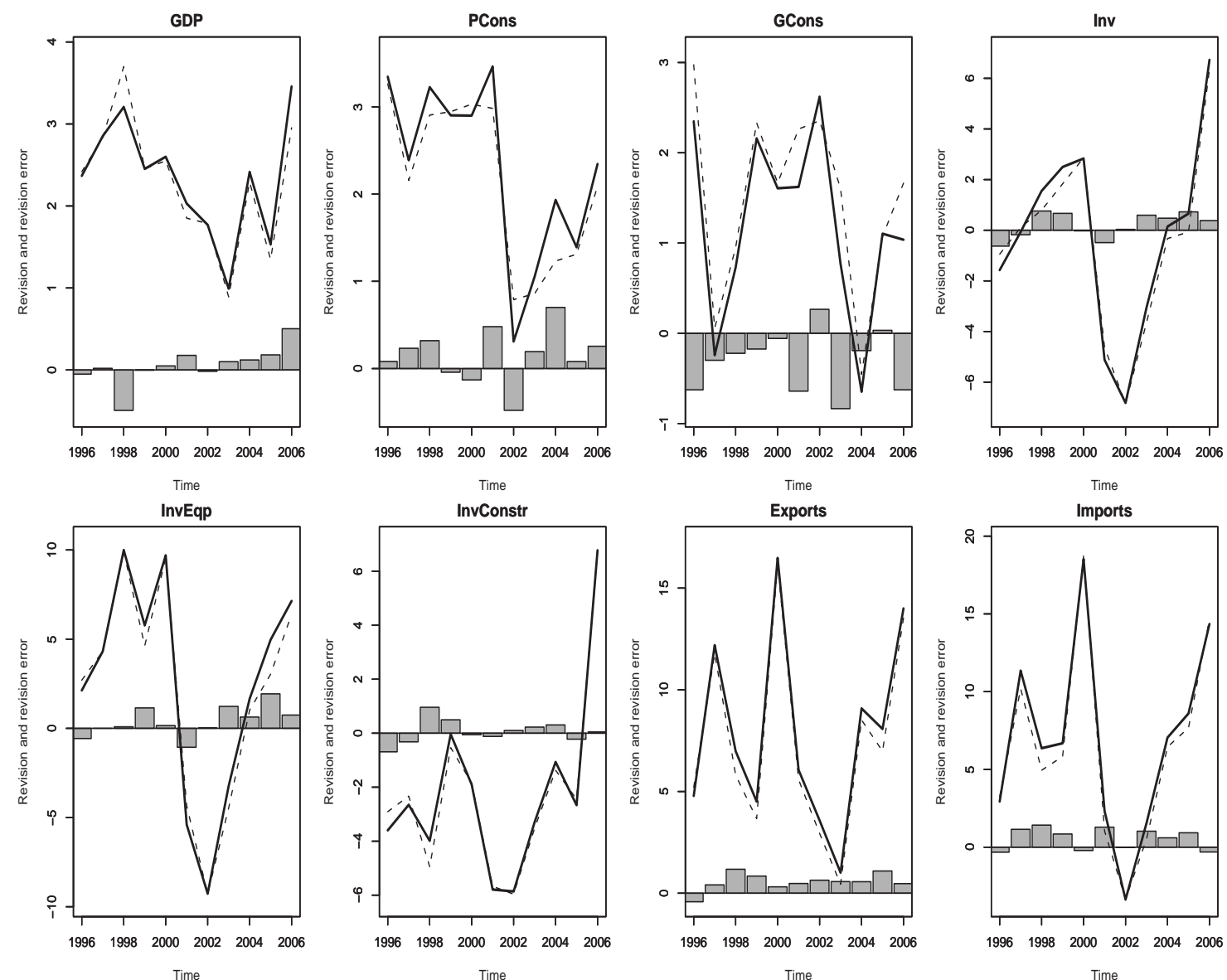
Figure 5: First statistical publication $(t+1 / 4)$ vs. final real data $(t+1)$, 1996-2006
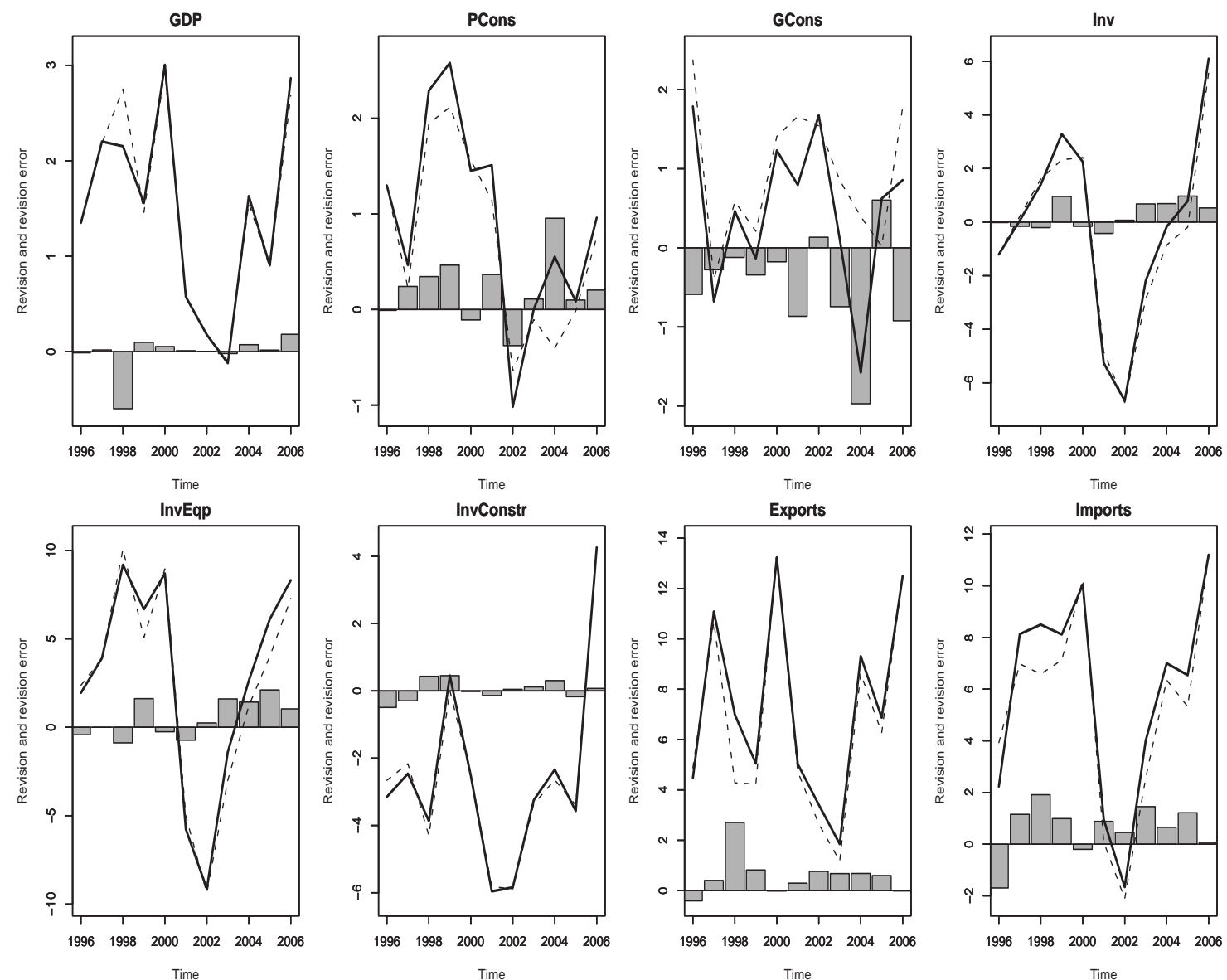
Figure 6: Distribution of the revision errors of the nominal variables
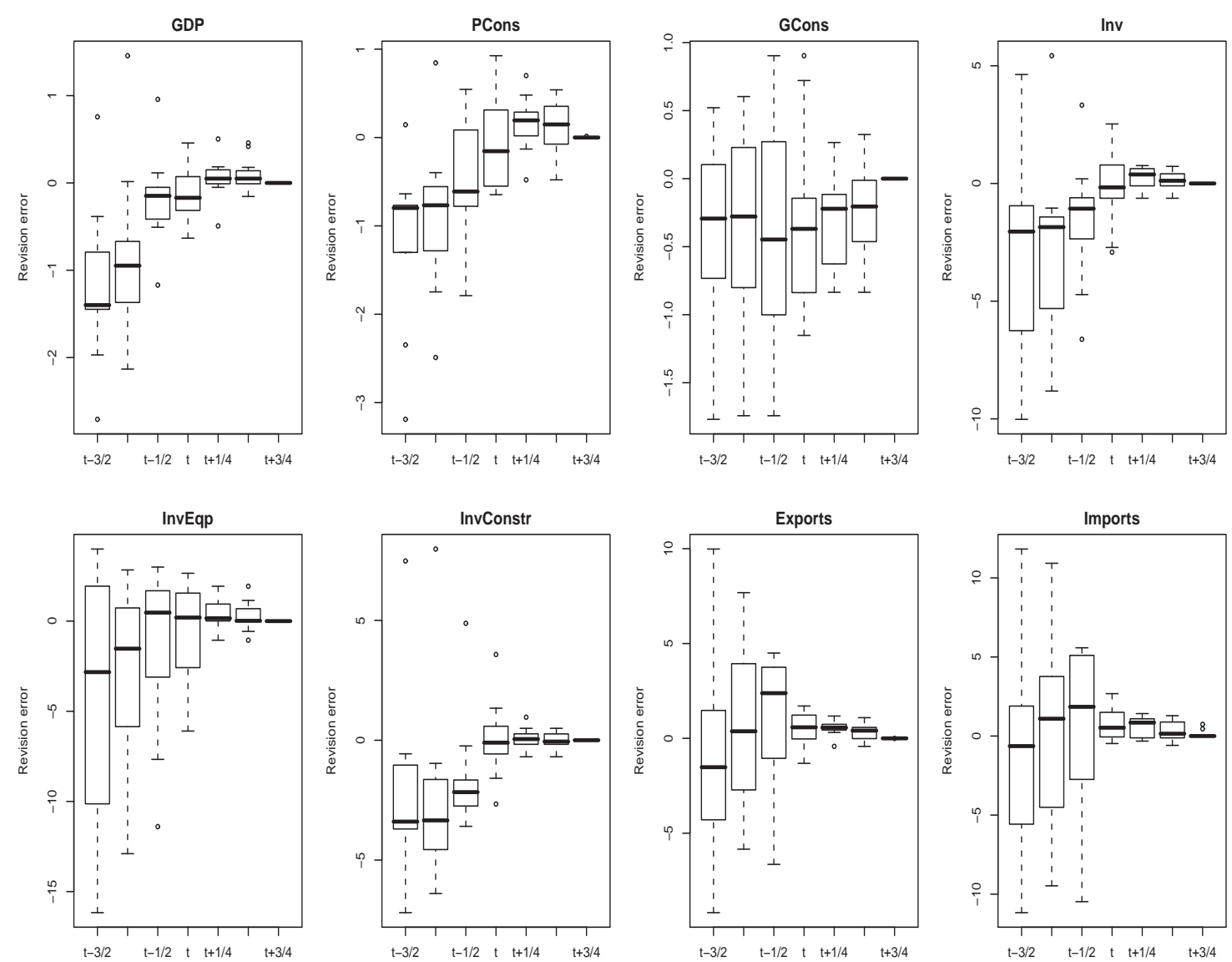
Figure 7: Distribution of the revision errors of the real variables
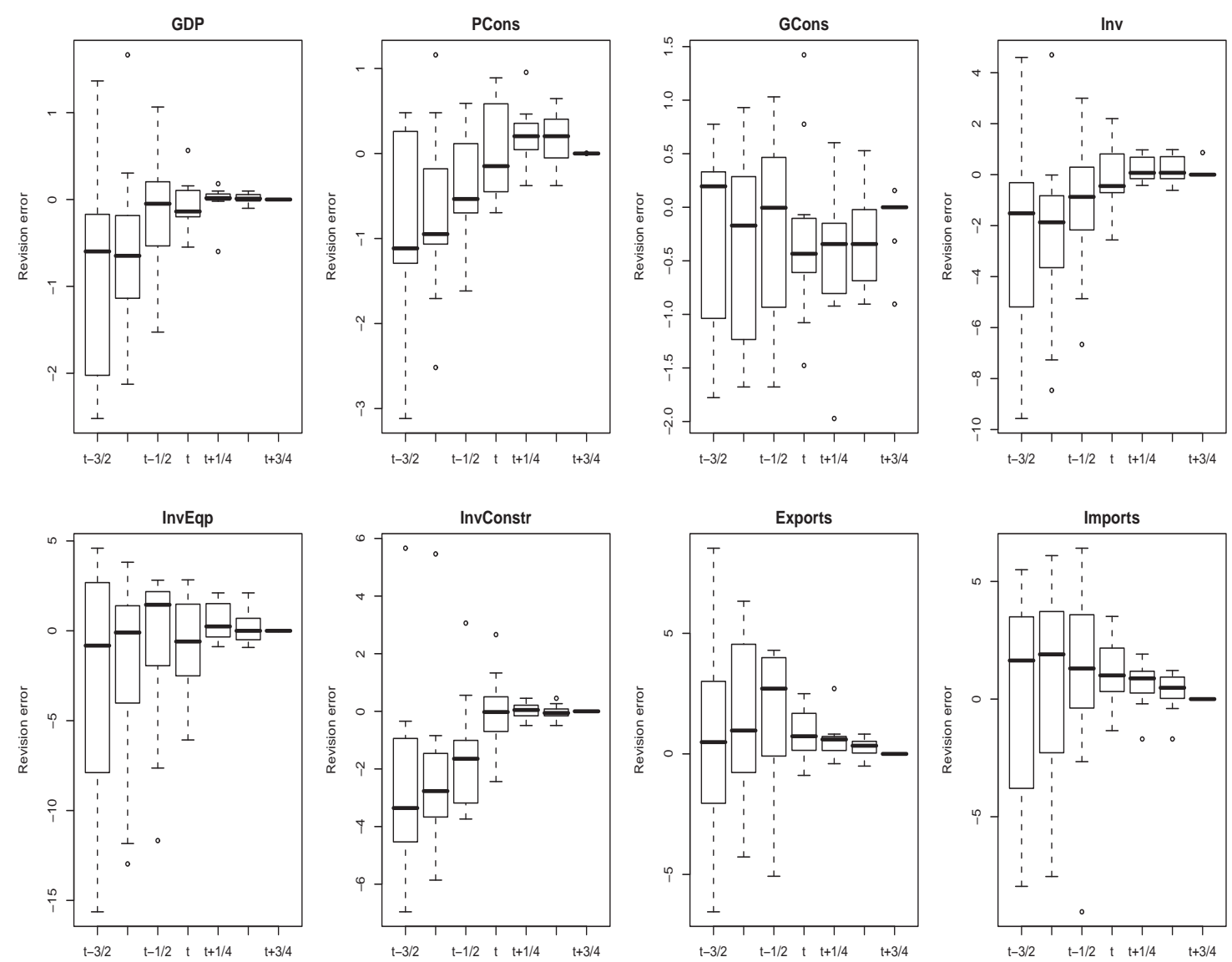
Figure 8: SNR of the nominal variables
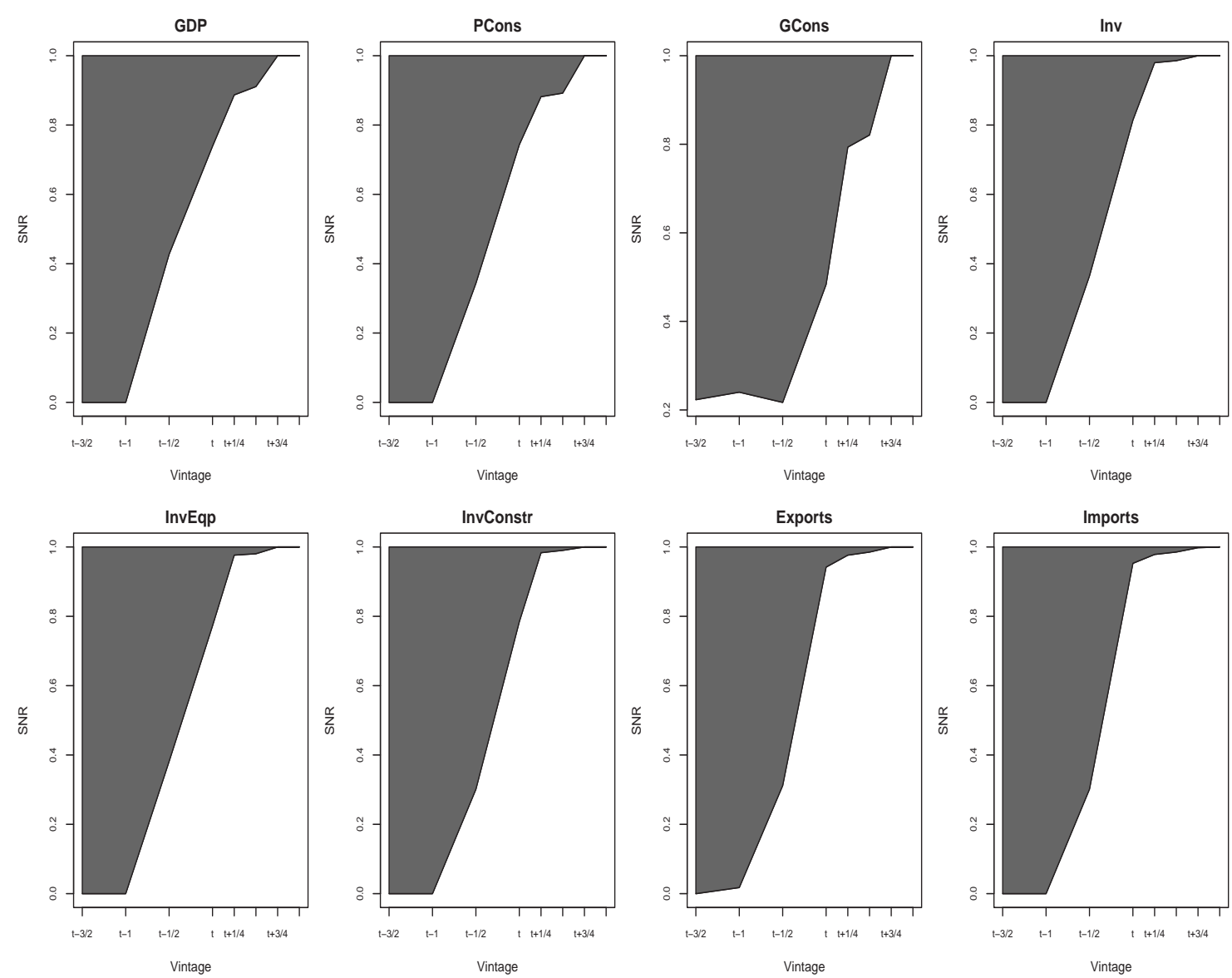
Figure 9: SNR of the real variables
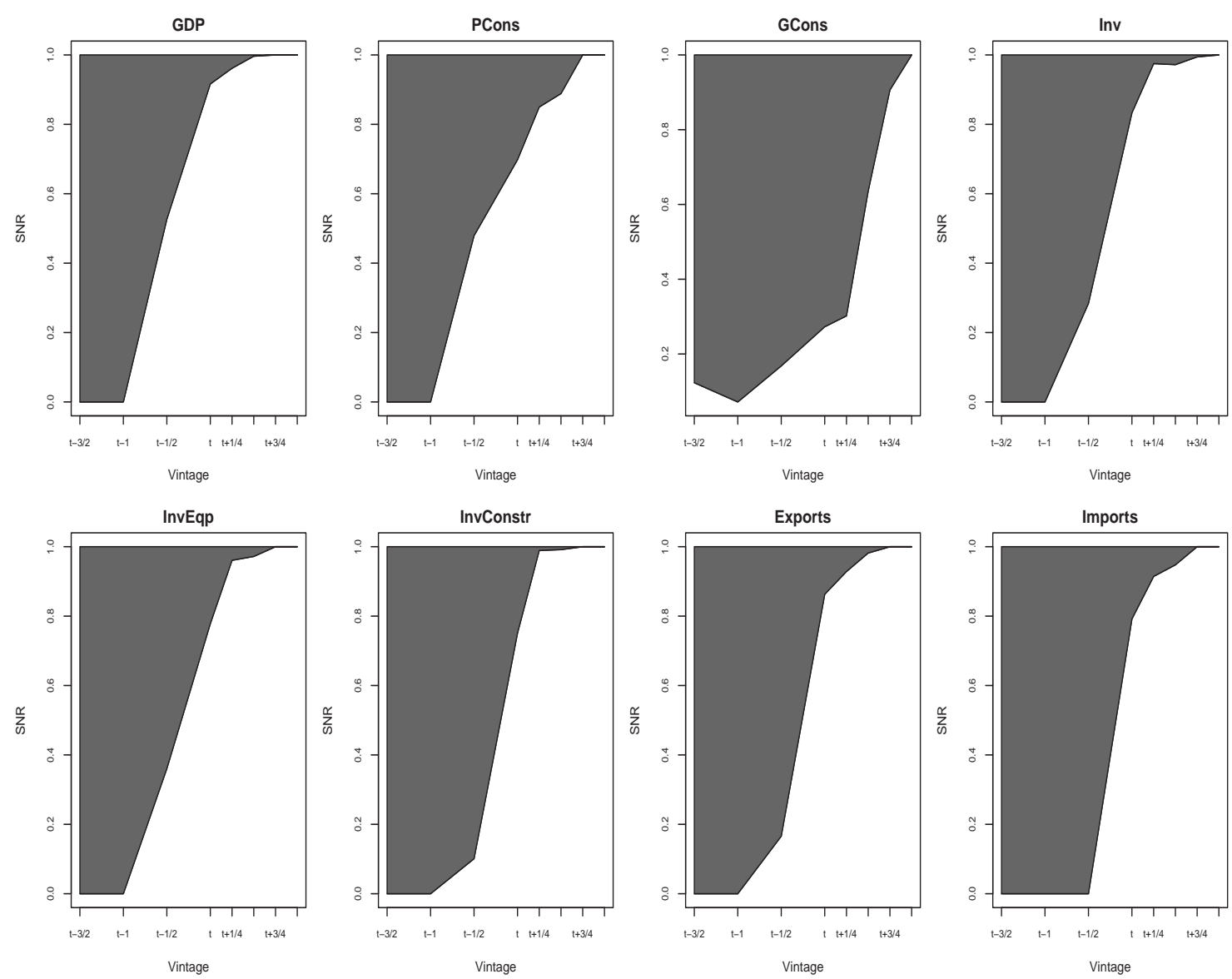